\title{
A terapia ocupacional social nos congressos brasileiros (1997-2007): desafios e debates de um campo emergente
}

\section{The debate of social occupacional therapy in brazilian congresses (1997-2007): challenges and debates of an emerging field}

\author{
Tiy de Albuquerque Maranhão Reis ${ }^{1}$, \\ Denise Dias Barros ${ }^{2}$, Iris Yuri Uchidomari ${ }^{3}$
}

\begin{abstract}
REIS, T. A. M.; BARROS, D. D.; UCHIDOMARI, I, Y. A terapia ocupacional social nos congressos brasileiros (1997-2007): desafios e debates de um campo emergente. Rev. Ter. Ocup. Univ. São Paulo, v. 21, n. 2, p. 111-120, maio/ago. 2010.

RESUMO: Neste artigo, busca-se demonstrar o desenvolvimento e o crescimento da Terapia Ocupacional Social como campo de atuação e de pesquisa no cenário profissional e acadêmico brasileiro. Para tal realizou-se levantamento e análise - qualitativa e quantitativa - de trabalhos apresentados nos congressos nacionais entre os anos de 1997 e 2007. O desenvolvimento da Terapia Ocupacional Social permite apreender, ainda que parcialmente, as maneiras pelas quais questões relativas V4aos processos sociais da sociedade brasileira vêm sendo abordadas por terapeutas ocupacionais em seu cotidiano de trabalho ou nos contextos de formação profissional. A partir da análise dos trabalhos em cada congresso foi possível observar as inovações e diferenciações metodológicas surgidas na Terapia Ocupacional que se diferenciam de abordagens de caráter clínico. Trata-se de perceber a diferença nem sempre evidente, que separa uma abordagem de saúde em contextos marcados por problemáticas sociais de uma abordagem que focaliza as próprias questões sociais vivenciadas por grupos sociais definidos, desenvolvendo metodologias e bases teóricas pertinentes.
\end{abstract}

DESCRITORES: Terapia ocupacional/métodos; Terapia ocupacional/tendências; Vulnerabilidade social; Congressos; Terapia ocupacional.

* Este trabalho decorre de reflexões desenvolvidas na dissertação de mestrado, intitulada "A Terapia Ocupacional Social: Análise da Produção Científica do Estado de São Paulo".

1. Mestre em Ciências da Reabilitação pela Universidade de São Paulo.

2. Doutora em sociologia, Departamento de Fisioterapia, Fonoaudiologia e Terapia Ocupacional da Faculdade de Medicina da Universidade de São Paulo. Programa de Pós-graduação em Ciências da Reabilitação da Faculdade de Medicina da Universidade de São Paulo.

3. Terapeuta Ocupacional pela Universidade de São Paulo, Projeto Metuia.

Endereço para correspondência: tiyreis@yahoo.com.br 


\section{INTRODUÇÃO}

fim de contribuir para o debate e discussão dos
caminhos pelos quais a Terapia Ocupacional
Social vem se desenvolvendo no Brasil, das práticas que a sustentam, das pesquisas que se processam e das questões por ela abordadas, procedeu-se a levantamento e análise das publicações/trabalhos de Terapia Ocupacional Social em seis congressos brasileiros da categoria, compreendidos entre 1997 e 2007.

Os congressos revelaram-se fontes relevantes para tal averiguação, dado que promovem o encontro de experiências e/ou reflexões oriundas do ensino (meio acadêmico) e do cotidiano de trabalho de diversos terapeutas ocupacionais (mercado de trabalho), além de darem acesso a parte importante da produção científica da área.

Desse modo, ao pesquisar as publicações dos congressos foi possível analisar um conjunto abrangente da produção científica da Terapia Ocupacional, além de mapeála em termos de diferentes áreas de atuação e distribuição geográfica no país. Os critérios utilizados para a análise e seleção dos trabalhos foram: 1) Trabalhos ou estudos que ocorreram em programas e/ou instituições públicas ou conveniadas da assistência social, da justiça, da educação e/ ou da cultura; 2) Reflexões sobre a responsabilidade social e o papel ético-político dos terapeutas ocupacionais; 3) Trabalhos que retratassem a constituição do campo social na Terapia Ocupacional e seus pressupostos teórico - metodológicos; 4) Questões relativas ao ensino da Terapia Ocupacional no campo social; 5) Discussões e análises de programas e projetos de extensão universitária voltados para a participação social e que ocorressem em contextos comunitários ou territoriais, cuja população-alvo não tenha sido definida exclusivamente por problemática de saúde/doença, por processos de tratamento, ou abordagens desenvolvimentistas; 6) Discussões e análises de programas sociais e/ou culturais de organizações não governamentais $\left(\mathrm{ONG}_{\mathrm{s}}\right)$, associações, ou universidades, voltados a grupos, pessoas e/ou comunidades desfavorecidas social e economicamente e/ou marcados por práticas culturais diferenciadas; 7) Trabalhos que se destinavam á análise de políticas públicas e/ou redes de atenção a populações em situação de vulnerabilidade social; 8) Discussões e análises de programas sociais destinados à profissionalização ou ao acesso ao mercado de trabalho de populações em situação de risco ou vulnerabilidade social, e cuja caracterização, enquanto grupo social, não se desse em função de problemática de saúde.

Foram excluídos os trabalhos que apresentavam abordagens clínicas, ou aqueles centrados em questões envolvendo saúde, processos de tratamento e reabilitação. Não foram considerados igualmente os textos que traziam propostas educativas com vistas à aquisição de habilidades cognitivas, sensoriais ou motoras.

\section{Intercessões e diálogos entre áreas - as diferenças surgem dos detalhes}

Os trabalhos foram classificados, segundo os critérios mencionados, em três grupos: 1) trabalhos com foco e abordagem social; 2) trabalhos que lidam com questões discutidas no campo social, embora nele não se insiram. Eles apresentam pontos de convergência com trabalhos de natureza social, utilizando, porém, metodologias clínicas, de saúde coletiva, ou ainda de desenvolvimento global em seus aspectos cognitivos, emocionais, comportamentais, psíquicos ou físicos; 3 ) trabalhos que desenvolvem outras abordagens.

Julgou-se importante discutir aqui mais detalhadamente a diferenciação adotada entre os dois primeiros grupos de trabalhos, dado que os desafios de sua classificação e análise revelam diferenças metodológicas fundamentais.

Desse modo, em alguns trabalhos foram descritas atuações relativas aos processos de exclusão/inclusão sociais e à ausência de acesso a direitos fundamentais decorrentes do comprometimento de saúde apresentado pelo sujeito ou grupo. Em tais situações, a intervenção do terapeuta ocupacional foi percebida como decorrente de uma abordagem de saúde coletiva, pois era direcionada a aspectos que resultavam de uma condição de saúde ou de desenvolvimento desfavorável, temporária ou permanentemente.

Esses trabalhos não foram selecionados, uma vez que a ação do terapeuta deu-se em função da préexistência de uma problemática de saúde que levou a um comprometimento do cotidiano e a um agravamento do grau de desvantagem ou exclusão social apresentado, ou seja, aqueles em que, na ausência de um quadro clínico de base, a intervenção do profissional não ocorreria.

O trabalho "Estudo de caso: território como espaço terapêutico, uma abordagem em reabilitação" constitui um exemplo. Trata-se do acompanhamento individual de uma adolescente que apresentava leucemia linfóide aguda. Os objetivos descritos foram:

1. conhecer a adolescente no espaço em que habita; 2 . estimulá-la para o retorno ao convívio social; 3. realizar acompanhamento dos problemas funcionais advindos 
REIS, T. A. M. et al. A terapia ocupacional social. Rev. Ter. Ocup. Univ. São Paulo, v. 21, n. 2, p. 111-120, maio/ago. 2010.

da hemiparesia; 4. dialogar permanentemente com os equipamentos sociais do território para apoiar sua rede de suporte (MALFITANO et al., 2001, p. 99).

O acompanhamento foi realizado levando em conta tanto as necessidades de reabilitação da jovem quanto suas demandas em relação a uma maior participação e circulação social no que se refere, por exemplo, ao acesso à educação: "Busca-se a diminuição de suas desvantagens sociais, construindo possibilidades de retorno à escola e de inclusão social" (MALFITANO et al., 2001, p. 99).

Porém, a atuação no âmbito escolar deu-se em função da problemática de saúde e não somente como uma questão de direito à educação, que todo jovem possui, apresentando ou não patologia ou deficiência. Esse é um ponto que diferencia uma abordagem clínica, ou de saúde/ reabilitação, de uma abordagem social.

Nesta última, a problemática social enfrentada, bem como o alijamento dos direitos de cidadania, são focos do trabalho do profissional, enquanto o acesso a programas de saúde, de reabilitação e/ou tratamento são vistos como parte do complexo entremeio de necessidades e demandas que o sujeito, não mais individual, e sim coletivo, apresenta. Portando, atua-se num movimento inverso, que vai do direito ao acesso à conquista do acesso, seja em relação à saúde, à educação, à cultura ou ao lazer, e não da saúde para a efetiva conquista de direitos, como o percurso assinalado no trabalho citado.

Saúde, educação, moradia, segurança, acesso à cultura e ao lazer fazem parte das garantias dos mínimos sociais, e por esse motivo são vistos como consequências do exercício da cidadania para toda e qualquer pessoa, independente de sua condição, por exemplo, de saúde. É dessa maneira que se apresentam as abordagens de Terapia Ocupacional Social, as quais não se definem a partir das características da população, e sim do grau de distanciamento em que essa população se encontra do exercício de seus direitos fundamentais.

A população - alvo da terapia ocupacional social é justamente aquela cujas maiores necessidades configuramse com base em sua condição de excluída do acesso aos bens sociais e cuja problemática se manifesta pelo agravamento das condições de vida a que está submetida. Tal problemática pode ser identificada com a noção de pobreza ou também entendida como uma situação de vulnerabilidade, de 'apartação', na medida em que o acesso aos direitos de cidadania, mesmo que constitucionais, é diferenciadamente atribuído, traduzindo-se numa experiência de não cidadania, de não pertencimento (ESCOREL, 1999, p. 23-81 apud GALHEIGO, 2005, p.34-35).
Em alguns trabalhos foram descritas ações comunitárias e territoriais desenvolvidas pelo terapeuta ocupacional, tanto em atendimentos fora dos equipamentos de saúde, quanto na mediação da relação da pessoa atendida com outros equipamentos de educação, culturais e de serviços, em que este profissional atua como facilitador no processo de inclusão social, de acesso a direitos e de exercício da cidadania.

Estas ações podem ser configuradas como de caráter social, se analisadas em separado, já que buscam construção de redes de suporte e garantia de direitos. Porém, ao se verificar o contexto em que foram produzidas, fica visível que ocorreram em consequência do processo de atenção em saúde destinado a uma pessoa que apresenta um quadro de doença ou deficiência.

A situação de exclusão apresentada pela adolescente do trabalho anteriormente citado foi alvo da ação do terapeuta, por ser considerada consequência da patologia apresentada. Em si e por si, ela não seria encarada como demanda pelo profissional de saúde, caso não houvesse $a$ priori alguma disfunção ou patologia.

Foram igualmente encontrados trabalhos que, embora mencionassem uma abordagem voltada à questão da cidadania, na verdade não a mantinham como foco de sua ação, como ocorreu em "Brinquedoteca: um espaço de exercício da cidadania infantil". O texto discorre sobre o atendimento a crianças "[...] com alterações no desenvolvimento neuropsicomotor [...] ” (OLIVEIRA et al., 2001, p.69) que estavam em um abrigo municipal, em função de abandono ou maus tratos. Os autores consideravam que a cidadania integrava sua abordagem do caso na medida em que se propiciava um ambiente acolhedor, acesso a lazer e a um brincar que possibilitasse às crianças um adequado desenvolvimento global, assinalando em seu parágrafo inicial que:

Um dos direitos assegurados pelo Estatuto da Criança e do Adolescente é o direito à educação e ao lazer, visando ao pleno desenvolvimento de sua pessoa, preparando-a para o exercício da cidadania e qualificação para o trabalho (OLIVEIRA et al., 2001, p.69).

Os autores não fazem qualquer referência a ações focadas nos processos de violação de direitos e de exclusão a que estavam submetidas, já que se tratava de crianças institucionalizadas por situações de vitimização. No texto é igualmente descrito o modo como a brincadeira era utilizada como recurso para estabelecer processo com finalidades terapêuticas sem realizar qualquer discussão sobre as contradições e conflitos sociais presentes no contexto de vida das crianças (abandono, violência doméstica, pobreza). 
Da mesma forma, são colocadas questões relacionadas à deficiência como principais pontos a serem trabalhados, a fim de possibilitar uma melhor inteiração das crianças com o mundo:

A deficiência representa uma barreira entre a criança e os objetos que deve manipular, as pessoas, o mundo a descobrir e a imagem de si mesma que ela vai construir. $\mathrm{O}$ brincar pode minimizar essas barreiras, prevenindo outras conseqüências, assim como contribuir para um processo reabilitador de natureza terapêutica (OLIVEIRA et al., 2001, p.69).

É demonstrada, assim, a finalidade da intervenção: propiciar estímulo e apoio ao desenvolvimento saudável das crianças, como instrumento para que possam exercer sua cidadania, isto é, ambos, cidadania e desenvolvimento, não são trabalhados concomitantemente, e sim como sendo um anterior ao outro. Em outras palavras, a cidadania foi encarada como uma consequência do trabalho voltado para a melhoria das condições de desenvolvimento pessoal. Portanto, o trabalho foi, no âmbito das análises sobre o campo da Terapia Ocupacional Social, considerado como tendo uma identificação explícita com práticas na área da reabilitação e não do campo social, apesar de ocorrer em um abrigo, equipamento da rede de assistência social. A afinidade temática, bem como o cerne do trabalho (enfatizando o desenvolvimento e a reabilitação) ficam mais bem definidos ao serem discutidos seus resultados e conclusões:

[...] atualmente observa-se melhora na exploração e utilização do brinquedo de modo criativo e funcional, além de diminuição de agressividade, e conseqüente melhora no relacionamento entre as crianças e destas com técnicos e acadêmicos; melhora no desenvolvimento psicomotor, concentração e socialização (OLIVEIRA et al., 2001, p. 69).

Desse modo, ainda que seja mencionado desde o título, não houve, ao longo do texto do trabalho apresentado, referência a ações específicas com vistas à problemática social da população em questão.

Alguns trabalhos surgiram a partir de temáticas da área da saúde, mas foram ampliando sua ação ao longo de seu desenvolvimento, chegando ao conjunto de pessoas de um dado território. Neles há uma abordagem que assumiu progressivamente contornos comunitários, com participação de outros atores sociais, juntamente com profissionais e usuários. Esses trabalhos foram considerados como tendo uma abordagem social, pois não selecionaram a população - alvo de suas ações segundo recorte de saúde, e sim de demandas sociais. Neles encontra-se atuação envolvendo outros grupos da comunidade, com delineamento das ações com a própria população a que se destinavam, reconhecendo nesta o papel de interlocutor e participante ativo na criação de estratégias para o equacionamento das demandas que apresenta. Esse processo de transformação progressiva das concepções do trabalho, transitando de uma proposta de saúde para uma atuação de caráter mais abrangente, do ponto de vista do reconhecimento de necessidades e demandas da população em questão, pode ser observado no pôster Envelhecimento compartilhado: grupos comunitários - uma atuação possível em terapia ocupacional, no qual é descrito o percurso de um grupo de mulheres adultas e idosas, inicialmente atendidas em um Centro de Saúde Escola, com quadros de "[...] depressão e outras alterações emocionais" (ANTUNES; BORINI, 2001, p. 94).

Nota-se ainda que, após encerrado seu processo terapêutico, as integrantes do grupo solicitaram a continuidade dos encontros. Então "[...] estimulou-se a organização de um grupo para encontros fora do espaço do Centro de Saúde, aberto para a participação de outras pessoas da comunidade" (ANTUNES; BORINI, 2001, p. 94), além de terem sido estabelecidos contatos com lideranças da comunidade católica da região, que cederam o espaço para os encontros. Desse modo, as ações e objetivos do grupo extrapolaram o ambiente e os propósitos clínicos. Ao abrir-se para as demandas presentes no conjunto da população idosa da região, o trabalho viabiliza a criação de um espaço que lhes proporcionaria participação social diferenciada sem a medicalização da demanda. As autoras explicitam a nova dimensão e característica da abordagem que desenvolviam, distinguindo-a de uma abordagem clínica: “[...] percebemos que estamos construindo uma metodologia de trabalho para atuar em grupos comunitários, os quais possuem um caráter diferenciado dos grupos terapêuticos" (ANTUNES; BORINI, 2001, p. 94).

Pode-se compreender, assim, que, para efeito do presente estudo, foram consideradas abordagens de cunho social aquelas em que o exercício, o resgate, a construção de cidadania e o acesso a direitos são objetivos principais da atuação, e por isso devem ser alcançados mediante ações específicas e com finalidades definidas, e não como consequência de um trabalho realizado com outro enfoque, pedagógico ou terapêutico.

\section{A Terapia Ocupacional Social nos Congressos Brasileiros: análise e discussão dos dados}

Os seis Congressos Brasileiros de Terapia Ocupacional (CBTO) analisados ocorreram entre 1997 e 
REIS, T. A. M. et al. A terapia ocupacional social. Rev. Ter. Ocup. Univ. São Paulo, v. 21, n. 2, p. 111-120, maio/ago. 2010.

2007 (REIS, 2008) e, apesar de assumirem características próprias no tocante à classificação dos temas enfocados, no que se refere aos trabalhos de Terapia Ocupacional Social trouxeram muitas questões semelhantes e por vezes recorrentes.

O crescimento expresso em número de trabalhos apresentados em cada congresso, assim como o número de trabalhos de Terapia Ocupacional Social, pode ser observado na Tabela 1. Nela é possível notar a predominância de autores do estado de São Paulo na apresentação de trabalhos de Terapia Ocupacional Social, além da existência de estreita correlação entre a produção nesse campo e o ensino, tendo em vista a proximidade de muitos autores com Instituições de Ensino Superior (IES).

Tabela 1 - Distribuição dos trabalhos de Terapia Ocupacional apresentados em CBTO segundo data do congresso, número, natureza temática, procedência e vínculo de autores à instituições de ensino superior

\begin{tabular}{|c|c|c|c|c|c|}
\hline \multirow[b]{2}{*}{$\begin{array}{l}\text { CBTO } \\
\text { Data }\end{array}$} & \multirow[b]{2}{*}{$\begin{array}{l}\text { Número Total de Tra- } \\
\text { balhos Apresentados }\end{array}$} & \multicolumn{4}{|c|}{ TRABALHOS DE TERAPIA OCUPACIONAL SOCIAL } \\
\hline & & Número & $\begin{array}{l}\text { Trabalhos do Estado } \\
\text { de São Paulo }\end{array}$ & $\begin{array}{l}\text { Trabalhos de Outros } \\
\text { Estados ou Países }\end{array}$ & Trabalhos de Autores Ligados à IES ${ }^{2}$ \\
\hline 1997 & 32 & 1 & 1 & 0 & 1 \\
\hline 1999 & 260 & 13 & 12 & 1 & 11 \\
\hline 2001 & 421 & 23 & 20 & 3 & 17 \\
\hline 2003 & 247 & 14 & 9 & 5 & 9 \\
\hline 2005 & 439 & 21 & 17 & 4 & 19 \\
\hline 2007 & 472 & 33 & 29 & 4 & 30 \\
\hline TOTAL & 1871 & 105 & 88 & 17 & 87 \\
\hline
\end{tabular}

${ }^{1}$ Congresso Brasileiro de Terapia Ocupacional

${ }^{2}$ Instituições de Ensino Superior

No V CBTO (1997), realizado em Belo Horizonte, MG, sob o tema "Horizontes da Clínica à Pesquisa", foram apresentados 32 trabalhos, dentre os quais apenas um com temática social. Trata-se de uma reflexão crítica acerca dos programas tradicionais de profissionalização destinados a adolescentes provenientes de famílias de baixa renda e que, segundo análise da autora, se fundamentavam em práticas assistencialistas e/ou disciplinares. O trabalho visa também à conscientização dos terapeutas ocupacionais a respeito dos reais conteúdos discriminatórios e de culpabilização da população - alvo (adolescentes) pela problemática social enfrentada, conteúdos assinalados como sendo subjacentes à implementação de programas de profisssionalização (GALHEIGO, 1997).

O congresso seguinte, realizado em São Paulo (1999), cujo tema foi "Trajetórias e Perspectivas da Terapia Ocupacional", apresentou um aumento do número de trabalhos que se referiam à Terapia Ocupacional Social, sob a forma de relatos de experiências, além de reflexões sobre o surgimento e o desenvolvimento desse campo na Terapia Ocupacional.

Os trabalhos referentes ao campo social formaram um conjunto de 13 exposições, entre comunicações orais e pôsteres, em sua maioria expondo experiências e/ou reflexões sobre a área, desenvolvidas de maneira articulada a iniciativas de pesquisa e extensão de IES, quase todas sediadas no estado de São Paulo. Neste congresso, a Terapia Ocupacional Social ganhou um contorno mais definido, não somente em função de uma presença maior de trabalhos em comparação com o congresso anterior, como devido a sua maior visibilidade. Os organizadores classificaram e reuniram os trabalhos sob os títulos: "A terapia ocupacional contribuindo para o resgate do ser social e da cidadania", e "Abordagens de terapia ocupacional com grupos em situação de risco pessoal e social".

As denominações estabelecidas já sinalizavam o que se configuraria como um norteador para a caracterização do campo: a proposta de atuação fora do eixo estruturador saúde- 
doença e a definição de uma população-alvo caracterizada por demandas sociais, culturais e/ou identitárias.

Observa-se nos textos que o termo social é assumido não mais como um aspecto a ser considerado pelos terapeutas ocupacionais, mas como alvo organizador e estruturador da ação destes profissionais. Seu foco de atuação iria delinear ações para além do indivíduo e das problemáticas que seu corpo ou mente encerram, ou ainda, das consequências relacionais e de inclusão/exclusão sociais que delas decorrem.

No Congresso de 1999, observa-se a presença de trabalhos que discutem questões relativas a problemáticas surgidas nas dinâmicas e conflitos sociais enfrentados pela população atendida. Há também a compreensão de que o sujeito da ação deva ser entendido em seu contexto histórico e cultural, sendo suas demandas expressões individuais e de seu grupo social. Outro assunto abordado foi o surgimento da Terapia Ocupacional Social e o início de sua constituição enquanto campo de atuação e de conhecimento. Esses foram alguns dos temas discutidos naquele momento, e que serviriam mais tarde como base para outros trabalhos apresentados em congressos subsequentes.

Até este congresso, a produção relacionada ao campo social esteve predominantemente representada por autores do estado de São Paulo, vinculados direta ou indiretamente à IES (tendência que se manteve nos congressos restantes, como ilustra o Gráfico 1), o que parece apontar para uma forte influência, ou mesmo para o surgimento do processo de divulgação de novas práticas e reflexões relacionadas a esse campo, por profissionais paulistas, influenciando ou motivando trabalhos que surgiriam nos congressos seguintes.

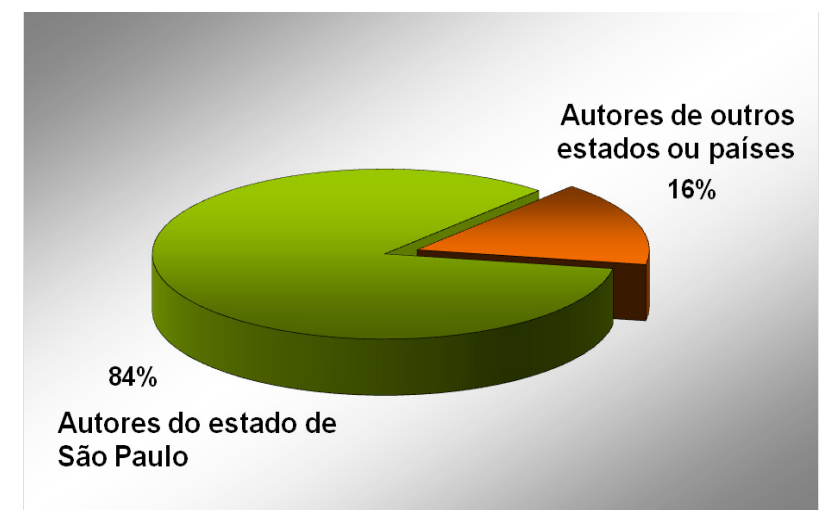

Gráfico 1 - Trabalhos de Terapia Ocupacional Social segundo a procedência de seus autores

No VII CBTO, realizado em Porto Alegre, RS (2001), o crescimento do número de trabalhos apresentados confirma-se como uma tendência, assim como o número de trabalhos com temática social (Tabela 1). Ao comparar esses dois valores, ao longo dos seis congressos pesquisados, é possível notar que ambos desenvolveram um comportamento semelhante, apresentando certo paralelismo nos momentos de crescimento e diminuição, e ligeira diferença no congresso de 2005, conforme demonstrado nos Gráficos 2 e 3 abaixo.

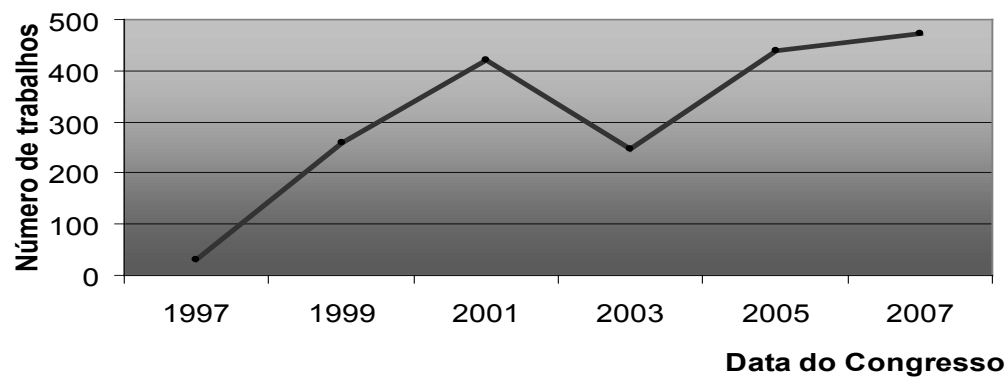

Gráfico 2 - Curva de crescimento do número total de trabalhos apresentados nos CBTO 
REIS, T. A. M. et al. A terapia ocupacional social. Rev. Ter. Ocup. Univ. São Paulo, v. 21, n. 2, p. 111-120, maio/ago. 2010.

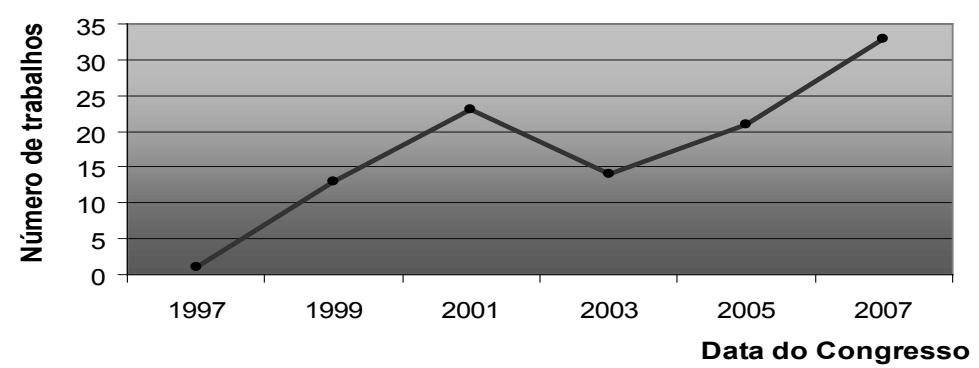

Gráfico 3 - Curva de crescimento do número de trabalhos de Terapia Ocupacional Social apresentados nos CBTO

No congresso de Porto Alegre houve, ao todo, 421 trabalhos apresentados, dos quais 23 foram classificados como tendo abordagem de caráter social. Eles se dividiram entre relatos de experiências de intervenção junto a populações em situação de risco pessoal e social, divulgação de projetos desenvolvidos a partir de parceria entre universidades e movimento social urbano, apresentações de iniciativas de geração de trabalho e renda, pesquisas, análises críticas sobre programas sociais governamentais e sobre o papel político do técnico.

O desemprego foi tema bastante focalizado como problemática a ser considerada e estudada pelo terapeuta ocupacional. Os trabalhos que se debruçaram sobre o assunto descreviam a diminuta participação social e o agravamento de processos de exclusão causados pelo desemprego, e mostravam alternativas surgidas da economia solidária e da organização de grupos de auto-gestão.

Os objetivos descritos por eles podem ser assim sintetizados:

Apresentar os princípios da Economia Solidária e articulálos às atuais tendências e experiências, onde a terapia ocupacional amplia sua ação para além dos serviços de saúde e assume compromissos com a inclusão social de populações marginalizadas, atuando em parceria com a comunidade (NICOLAU, 2001, p. 36).

Outra característica observada no Congresso de 2001 foi o fato de que 17 dos 23 trabalhos selecionados eram de autores vinculados à IES (Tabela 1) e se referiam a programas de extensão universitária, formação profissional ou pesquisa, enquanto os demais autores possuíam vínculos com projetos sociais, cooperativas de trabalho, ou órgãos do governo, na área da assistência e desenvolvimento social.

O VIII CBTO, realizado em Foz do Iguaçu (2003), apresentou perfil bastante atípico em relação ao movimento de progressiva estruturação e crescimento assumido em cada evento, pois registrou um número de trabalhos consideravelmente inferior ao do congresso anterior
(Tabela 1).

Dentre os temas abordados pelos trabalhos de Terapia Ocupacional Social, salientam-se: a atuação junto a grupos populacionais em situação de risco ou vulnerabilidade social, na perspectiva da efetivação de políticas setoriais a eles relacionadas e no apoio à construção de projetos de vida e alternativas de enfrentamento das diferentes faces da exclusão vivenciadas pelas populações descritas. São elas: crianças trabalhadoras em centros urbanos, mulheres ou adolescentes em situação de rua, adolescentes autores de atos infracionais, pessoas vivendo desemprego estrutural, crianças abrigadas. Foram apresentadas diferentes modalidades de atuação territorial, comunitária, ou em espaços públicos, além de experiências de apoio à organização de grupos comunitários. Como nos demais congressos analisados, é notória a presença de trabalhos referentes a pesquisas relacionadas ao ensino e a experiências de extensão universitária.

O IX CBTO realizou- se no ano de 2005, em Recife, Pernambuco. Neste evento foram debatidas questões metodológicas e de formulação teórica da Terapia Ocupacional Social. Houve, pela primeira vez em um congresso brasileiro, um curso específico voltado para essa temática.

No X CBTO, ocorrido em 2007, em Goiânia, Goiás, apenas alguns dos trabalhos selecionados identificam-se explicitamente como sendo de Terapia Ocupacional Social. A maioria dos trabalhos selecionados descreve suas ações, pesquisas e objetivos, sem mencionar filiação a campo de conhecimento específico, enquanto uma pequena parcela destes apresenta-se exercendo "práticas terapêuticas". Porém, na descrição de seus objetivos, abordagens e ações volta-se para o acesso aos direitos da população a que se refere, ou mesmo tendo como foco das demandas levantadas a vulnerabilidade social a que está submetido determinado grupo populacional, ou ainda, empenha esforços na elaboração de estratégias e alternativas para o estabelecimento ou ampliação de suportes sociais mais 
sólidos. Cabe ressaltar, porém, que ocorre um simpósio de Terapia Ocupacional Social como parte das atividades do congresso, além de palestras de autores do campo social, tanto brasileiros quanto estrangeiros, como Frank Kronemberg. Trata-se do I Simpósio de Terapia Ocupacional Social: Campo, Conhecimento e Intervenções, organizado em parceria com pesquisadores do Projeto Metuia - grupo interinstitucional de estudos, formação e ações pela cidadania de crianças, adolescentes e adultos em processo de ruptura das redes sociais de suporte. Desta forma, evidenciase o esforço de realização de um debate específico por ocasião de uma das mais importantes reuniões científicas da Terapia Ocupacional no país.

No que se refere ao conteúdo, os trabalhos trouxeram alguns temas até então não considerados em congressos anteriores, tais como: atuação profissional no campo social, a partir de um relato auto-biográfico (GERASSI, 2007); reflexões sobre a Terapia Ocupacional Social e suas conexões com o campo filosófico da complexidade (BOTTEON; CUNHA, 2007); desafios que os terapeutas ocupacionais enfrentam em sua relação com as organizações não governamentais e o terceiro setor (LOPES et al., 2007); análise da concepção de ocupação existente em um movimento social rural e sua relação com a constituição da identidade social (ACHÊ; OLIVEIRA, 2007); síntese das questões que vêm permeando o desenvolvimento do campo social na Terapia Ocupacional, incluindo as dificuldades da inserção profissional e a pouca comunicação que se estabelece entre autores que produzem conhecimento nessa área em diversos países.

Quanto às influências teóricas, os trabalhos de Terapia Ocupacional Social neste congresso partem, em sua maioria, de fontes bibliográficas e teóricas semelhantes. Há, porém alguns que não utilizam a bibliografia ou os autores considerados de referência para o campo. É interessante observar que estes últimos apresentam expressivos pontos de convergência e identificação com os demais, demonstrando que, mesmo tendo bibliografia diferenciada e tratando-se de experiências realizadas em diferentes regiões do país, há certa compatibilidade entre abordagens, temáticas e populações, sem a presença de discrepâncias marcantes. Isso parece indicar que o desenvolvimento da Terapia Ocupacional Social vem ocorrendo com uma coerência compartilhada e que retroalimenta seu delineamento enquanto campo de atuação e saberes próprios dentro da Terapia Ocupacional como um todo.

O crescimento numérico de trabalhos do campo social é bastante expressivo e apresenta comportamento semelhante ao da Terapia Ocupacional como um todo, conforme mencionado anteriormente. Em outras palavras, verifica-se um paralelismo entre momentos de aumento e diminuição (Gráficos 2 e 3). Porém, observou-se que o índice de crescimento da área, considerando-se do primeiro ao último CBTO analisado, foi de $3.200 \%$, mais que o dobro do índice de crescimento dos trabalhos de Terapia Ocupacional em sua totalidade, que foi de $1.375 \%$.

Cabe ressaltar que, a despeito do notável crescimento da representação da área nos CBTO, os altos valores se devem ao fato de tratar-se de um campo que faz parte de um universo profissional ainda pequeno. Sendo assim, mesmo pequenas variações em termos absolutos ganham visibilidade quando calculadas em termos percentuais. No Gráfico 4 é possível comparar esses dois índices, evento a evento.

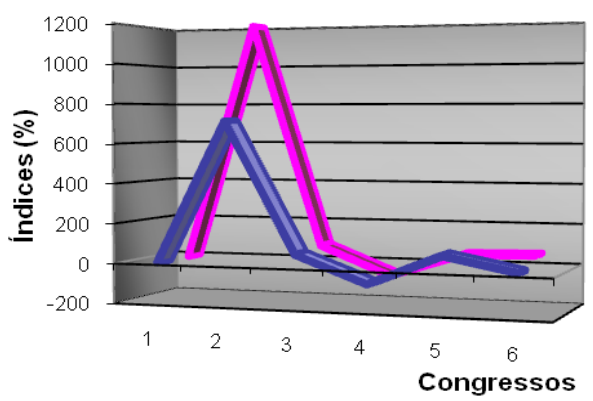

- Total de trabalhos Trabalhos de terapia ocupacional socia

Gráfico 4 - Comparação entre os índices de crescimento de trabalhos de Terapia Ocupacional Social e do total de trabalhos apresentados em cada Congresso Brasileiro de Terapia Ocupacional

Outro ponto relevante na produção relacionada ao campo social foi a predominância de autores do estado de São Paulo (que se verificou ao longo de todos os congressos pesquisados), responsáveis por $84 \%$ dos trabalhos relacionados ao campo social. Foi também evidente a importante influência de reflexões oriundas de profissionais ligados a instituições de ensino sobre o panorama de constituição do campo social na Terapia Ocupacional, já que representaram $83 \%$ dos trabalhos publicados. Essa expressiva participação de autores ligados à IES na produção relacionada ao campo social demonstra que sua estruturação, como campo de atuação e pesquisa para os terapeutas ocupacionais, tem recebido importante influência do meio acadêmico e com ele estabelecido diálogo contínuo.

\section{CONCLUSÃO}

A expansão que o campo social vem alcançando 
na Terapia Ocupacional brasileira, nos últimos anos, está intimamente relacionada a iniciativas de ensino, pesquisa e, sobretudo, extensão de programas universitários atentos à precarização das condições de vida e do acesso aos direitos fundamentais a que vem sendo historicamente submetida grande parte da população no Brasil. Somase a isso a recente regulamentação do SUAS, trazendo algumas contribuições conceituais importantes para a delimitação das especificidades desse campo, no que se refere aos destinatários das políticas de seguridade social, à necessidade de garantia dos mínimos sociais, bem como a seu caráter integrador com políticas de outras áreas.

A diversificação de trabalhos apresentados reflete a crescente atuação do terapeuta ocupacional nos espaços sociais, seja na assistência direta, ou participando de fóruns de discussão e conselhos de direitos, na formação de redes ou na proposição de políticas. A ampliação da atuação desses profissionais no campo social também se deu em função do aumento de organizações não governamentais no cenário social brasileiro e, de forma paralela, à crescente profissionalização do terceiro setor.

Convém salientar que a inserção do terapeuta ocupacional no terceiro setor vem encontrando uma série de desafios perante as contradições vivenciadas atualmente pelas organizações não governamentais brasileiras, como ressaltam Lopes et al. (2007). Porém, a crescente produção nos CBTO parece refletir o esforço de sistematização das reflexões e vivências desses profissionais, bem como as experiências e contribuições que vêm sendo engendradas em meio às imensas contradições presentes no bojo do emaranhado sócio-político e assistencial do país.

A Terapia Ocupacional Social está se estruturando, assim como o campo social assistencial, em um Brasil com uma história recente de regime totalitário e em que as políticas de transferência de renda são, no contexto atual, amplamente propagandeadas pelo governo, como principal alternativa no combate às desigualdades sociais e à pobreza, todavia sem impactos de natureza estrutural (DRUCK; FILGUEIRAS, 2007).

Finalmente, analisar os trabalhos publicados nos CBTO permitiu conhecer uma gama de projetos e programas sociais em que estão inseridos terapeutas ocupacionais, distribuídos por várias regiões do país, o desdobramento de reflexões oriundas do ensino em práticas que buscam a transformação social, o engajamento do técnico como agente desse processo e o modo como o terapeuta ocupacional vem se integrando ao campo como trabalhador social, e não como trabalhador de saúde no campo social (o que retrata a mudança de foco do trabalho do terapeuta, que até então se centrava no sujeito, adquirindo preocupações mais coletivas relativas às dinâmicas e contradições sociais vivenciadas por esse sujeito e pelo grupo social a que pertence). Essa diferenciação nas atuações dos terapeutas ocupacionais tornou-se progressivamente visível, e com ela a Terapia Ocupacional conhece novos desafios e mais uma possibilidade de intervenção e de desenvolvimento.

REIS, T. A. M.; BARROS, D. D.; UCHIDOMARI, I. Y. The debate of social occupacional therapy in brazilian congresses (1997-2007): challenges and debates of an emerging field. Rev. Ter. Ocup. Univ. São Paulo, v. 21, n. 2, p. 111-120, maio/ago. 2010.

\begin{abstract}
The aim of this work is to demonstrate the development and growth of social Occupational Therapy as a field of research and activity in the Brazilian academic and professional scenery. To reach this goal some research and analysis - both qualitative and quantitative - of several works presented in national congresses, between 1997 and 2007, took place. The development of Social Occupational Therapy allows, although partially, to understand the ways by which issues related to Brazilian society social processes are being approached by occupational therapists in their daily working activities and professional graduation context. The analysis of each work collected provided abundant information concerning the innovations and methodological differentiation aroused in Occupational Therapy, which differ from clinical approaches. The goal of this observation is also to evidence the difference, not always visible, between a health approach to contexts socially marked by severe problems and a specifically social one, focused on the social issues experienced by certain social groups, with the development of pertinent theoretical methodology and basis.
\end{abstract}

KEY WORDS: Occupational therapy/methods; Occupational therapy/trends; Social vulnerability; Congresses; Occupational therapy. 
REIS, T. A. M. et al. A terapia ocupacional social. Rev. Ter. Ocup. Univ. São Paulo, v. 21, n. 2, p. 111-120, maio/ago. 2010.

\section{REFERÊNCIAS}

ACHÊ, P.; OLIVEIRA, A. S. A ocupação no MST: percepção e compreensão dos sem-terras - um olhar da terapia ocupacional. In: CONGRESSO BRASILEIRO DE TERAPIA OCUPACIONAL, 10., 2007. Anais. Goiânia, 2007. CD-ROM.

ANTUNES, D. C.; BORINI, M. L. O. Envelhecimento compartilhado: grupos comunitários - uma atuação possível em Terapia Ocupacional. In: VII CONGRESSO BRASILEIRO DE TERAPIA OCUPACIONAL, 7., 2001. Anais. Porto Alegre: Instituto Porto Alegre, 2001. p. 94.

BOtTEON, L. M.; CUNHA, C. D. Refletindo a terapia ocupacional social a partir da complexidade. In: CONGRESSO BRASILEIRO DE TERAPIA OCUPACIONAL, 10., 2007. Anais. Goiânia, 2007. CD-ROM.

DRUCK, G.; FILGUEIRAS, L. Política social focalizada e ajuste fiscal: as duas faces do governo Lula. Rev. Katálisis, v. 10, n. 1, p. 24-34, jan./jun. 2007.

GALHEIGO, S. M. O social: idas e vindas de um campo de ação em terapia ocupacional. In: PÁDUA, E. M. M.; MAGALHÃES, L. V. (Orgs.). Terapia ocupacional. Campinas: Papirus, 2005. p. 29-46.

GALHEIGO, S. M. Educação e trabalho: velhos dilemas, novos rumos nos programas de profissionalização para adolescentes. In: CONGRESSO BRASILEIRO DE TERAPIA OCUPACIONAL, 5., SIMPÓSIO LATINO-AMERICANO DE TERAPIA
OCUPACIONAL, 1997. Anais. Belo Horizonte: Associação dos Terapeutas Ocupacionais de Minas Gerais, 1997. v. 1. p. 158-160.

GERASSI, M. I. Resignificando identidades: a minha trajetória no campo social. In: CONGRESSO BRASILEIRO DE TERAPIA OCUPACIONAL, 10., 2007. Anais. Goiânia, 2007. CD-ROM.

LOPES, R.E.; MALFITANO, A. P. S.; BORBA, P. L. O. Problematizando a atuação do terapeuta ocupacional nas organizações nãogovernamentais. In: CONGRESSO BRASILEIRO DE TERAPIA OCUPACIONAL, 10., 2007. Anais. Goiânia, 2007. CD-ROM.

MALFITANO, A. P. S., et al. Estudo de caso: território como espaço terapêutico uma abordagem em reabilitação. In: CONGRESSO BRASILEIRO DE TERAPIA OCUPACIONAL, 7., 2001. Anais. Porto Alegre: Instituto Porto Alegre, 2001. p. 99.

NICOLAU, S. M. Terapia ocupacional e economia solidária: uma parceria promissora. In: CONGRESSO BRASILEIRO DE TERAPIA OCUPACIONAL, 7., 2001. Anais. Porto Alegre: Instituto Porto Alegre, 2001. p. 36.

OLIVEIRA, I. B. S.; et al. Brinquedoteca: um espaço de exercício da cidadania infantil. In: CONGRESSO BRASILEIRO DE TERAPIA OCUPACIONAL, 7., 2001. Anais. Porto Alegre: Instituto Porto Alegre, 2001. p. 69.

REIS, T. A. M. A terapia ocupacional social: análise da produção científica do estado de São Paulo. 2008. 87 f. Dissertação (Mestrado) - Universidade de São Paulo, Faculdade de Medicina, 2008. 